\section{Effect of Gibberellic Acid on Flowering of Apple Trees}

IT has been shown by Sironval et al. ${ }^{1}$ that gibberellic acid $\left(\mathrm{GA}_{3}\right)$ affects growth of the main shoots in apple trees (var. Golden Delicious) and apical dominance. Apple-trees treated with 300 p.p.m. G.A $\hat{A}_{3}(1-2 \mathrm{ml}$. given twice a week on the apical bud and young leaves) throughout the growing season are greater and form twice as many lateral shoots as control trees.

On the other hand, it has long been elaimed by gardeners that, in apple trees, growth of the shoots and flowering are antagonist processes. Indeed, Wareing and $\mathrm{Nasr}^{2}$, investigating the effects of gravity on growth and flower formation, have shown that apple trees (apple rootstock No. 3436) grown horizontally have a reduced growth, but initiate more flowers than apple trees grown vertically (gravimorphism). We found it interesting to investigate flower formation of apple trees treated with gibberellic acid $\left(\mathrm{GA}_{3}\right)$.

Apple trees (var. Golden Delicious) were treated with $G^{4} A_{3}$ (100 and 300 p.p.m.) in 1961 according to the method of Sironval et al. A.t the end of the growing season, the plants treated with 300 p.p.m. $G_{3} A_{3}$ were greater than the control plants (increase of about $15 \mathrm{~cm}$ ); the plants treated with 100 p.p.m. GA $_{3}$ were also a little higher than the controls. The treated plants bore 9-11 lateral shoots, while the controls bore only 4-5 lateral shoots. In the spring of 1962 the apple trees were re-examined for flowering.

Table 1 gives the absolute number of flower buds found on the whole plant and also on the main and lateral shoots. It is seen that treated plants formed more flower buds than control plants. The increase in the absolute number of flower buds resulted chiefly from the lateral shoots, which were more numerous in treated plants; the main shoots gave a similar absolute number of flower buds in treated and control plants.

Fig. 1 gives the percentages of the different categories of buds found on main and lateral shoots, and on the whole plants: dormant buds, vegetative and flower buds.

(1) On main shoots there was nearly the same percentage of dormant buds in treated and control plants. The percentage of flower buds was, however, lower in treated than in control plants.

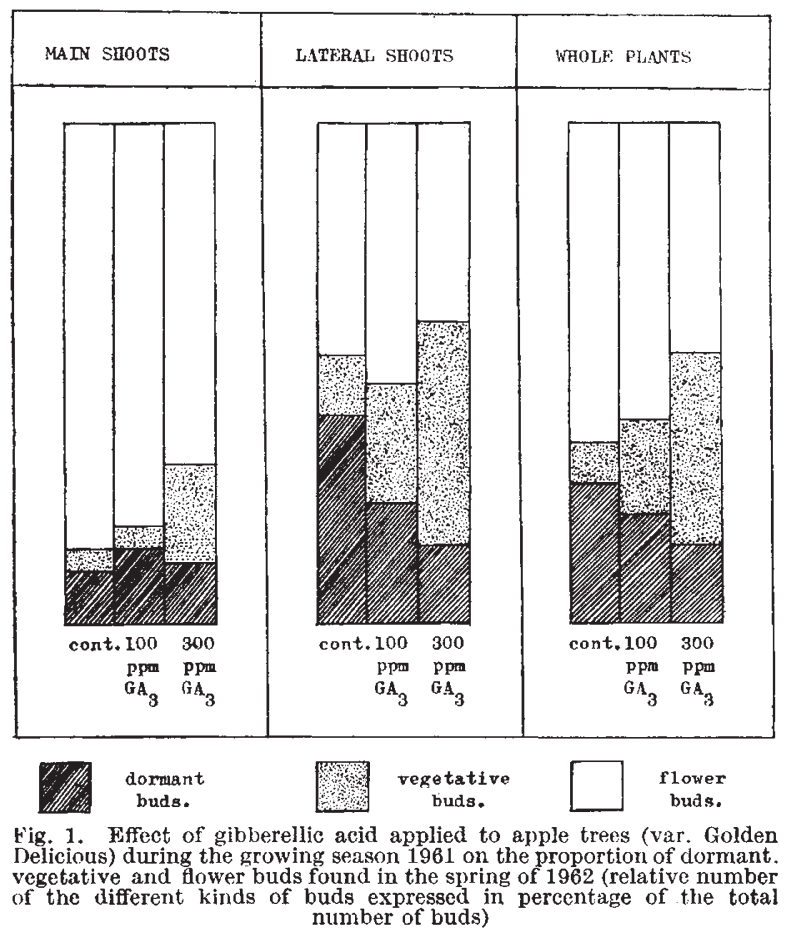

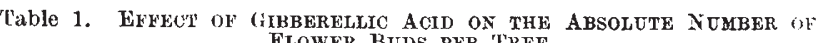

\begin{tabular}{|c|c|c|c|}
\hline Serics & Whole plant & Main shoots & Lateral shoots \\
\hline $\begin{array}{l}\text { Controls } \\
100 \text { p.p.m. GA }\end{array}$ & $\begin{array}{l}38 \\
58 \\
56\end{array}$ & $\begin{array}{l}24 \\
21 \\
19\end{array}$ & $\begin{array}{l}14 \\
37 \\
37\end{array}$ \\
\hline
\end{tabular}

(2) On lateral shoots, the percentage of dormant buds was lower in treated plants than in control plants. The percentage of flower buds was again lower in treated than in control plants, except for the 100 p.p.m. treatment.

(3) For the whole plant, we found a decrease of the percentage of dormant buds and a decrease of the percent. age of flower buds in treated trees when compared with the control ones.

This means that if, in absolute value, the number of flower buds is higher in $\mathrm{GA}_{3}$-treated apple trees, owing to the great increase of the number of buds present on the lateral shoots, the percentage of flower buds is decreased when $\mathrm{GA}_{3}$ is applied.

It may be concluded that the enhancement of the growth of the shoots (both main shoots and lateral shoots) by gibberellic acid treatment corresponds to a relative decrease in the capacity of the buds to form flowers. The result is similar to that obtained by Wareing and Nasr using gravimorphism; it corresponds to the relation generally claimed in practice between rate of growth of the shoots and flower formation in apple trees.

C. SrRonval
Laboratory of Plant Physiology (IRSIA),

R. Marcelli

Research Station of Gorsem,

Gorsem-St. Truiden, Belgium.

${ }^{1}$ Sironval et al., Gartenbauwissenschaft, 27,295 (1962).

${ }^{2}$ Wareing, P. F., and Nasr, T., Nature, 182, 379 (1958).

\section{ENTOMOLOGY}

\section{Feeding Stimulants required by a Polyphagous Insect, Schistocerca gregaria}

IT has been shown by Hamamura et al. ${ }^{1}$ that foort selection in the silkworm larva (Bombyx, mori) is controlled by three chemical factors which they have called the attractant, the biting and the swallowing factors.

The desert locust (Schistocerca gregaria), which is a polyphagous insect, appears to require only the attractant and the swallowing factor to evoke the normal feeding behaviour. This behaviour pattern begins with the locust approaching the food and then lowering the tips of the antennæ and palps on to the food surface and biting. Sustained feeding then continues without further testing of the food with the antennx; the palps alone are used to test the food as the insect feeds.

The experiments described here were performed to determine whether a fow widely dispersed plant compounds would stimulate feeding by Schistocerca, or whether a number of compounds each present in a limited range of plants would be required. A series of extracts were made from plants on which the locust normally feeds, and these extracts were then run singly on to filter paper circles. The solvent was removed from the papers, and these were then placed in cages containing locusts. It wa. observed that the ether extract alone stimulated a marker? testing behaviour in the locusts, and this testing always terminated with a single bite after which the locust would test the surface of the filter paper elsewhere. It was therefore assumed that the ether extract contained the attractant factor, and possibly a biting factor.

To determine whether this stimulant was the sane substance or substances in the plants that were tested, a series of paper chromatograms were made using the ether extract and a variety of solvents and solvent mixtures. The chromatograms were then dried and placed in cages with locusts. Certain solvents (phenol, acetic acid) werc found to be retained on the chromatograms sufficiently to 